\title{
Behavioral, Endocrine, and Immunological Correlates of Immigration by an Aggressive Male into a Natural Primate Group
}

\author{
Susan C. Alberts, ${ }^{*} \dagger$ Robert M. Sapolsky, $\dagger \ddagger$ \\ and Jeanne Altmann*-†, $\$$ \\ ${ }^{*}$ Department of Ecology and Evolution, University of Chicago, Chicago, Illinois 60637; \\ $\dagger$ Institute for Primate Research, National Museums of Kenya, Karen, Nairobi, \\ Kenya; $\ddagger$ Department of Biological Sciences, Stanford University, Stanford, \\ California 94305; and \$Department of Conservation Biology, Chicago \\ Zoological Society, Brookfield, Illinois
}

\begin{abstract}
A very aggressive young adult male entered one of three long-term study groups of yellow baboons, Papio cynocephalus, approximately 3 weeks after an immobilization project began. The immigrant male's rate of agonistic encounters was appreciably higher than average, and these interactions disproportionately involved adult females as targets. Basal cortisol concentrations were higher and total lymphocyte counts lower for individuals immobilized during the immigration situation than for other individuals; these effects were greater for females than for males. Among animals whose endocrine data were obtained during the immigration period, some were specific targets of the immigrant male's aggression and others were not. Lymphocyte counts were significantly lower for those individuals who were victims of the male's aggression than for noninvolved individuals; a nonsignificant tendency toward higher basal cortisol concentrations for victims was observed as well. The immigrant male himself had a high basal cortisol concentration, a low lymphocyte count, and a testosterone concentration that was triple the average for adult males and almost double the second highest value in the population. (c) 1992 Academic Press. Inc.
\end{abstract}

Savannah baboons, Papio cynocephalus, are among the largest and most sexually dimorphic of the monkeys. As is the case for most anthropoid primates, females stay in their group of birth throughout their lives, and males, by contrast, usually leave their natal group as young adults of 8 or 9 years of age. If males arc successful, they reproduce in one or a succession of other groups; immigration is most commonly into nearby groups (Samuels and Altmann, 1991). The entry of an individual into an integrated stable social group of primates is often a disruptive event; when the entering animal is an adult male in a species characterized by high levels of intrasexual competition, considerable aggression, involving adults of both sexes, often ensues (Dittus, 1977; Packer, 1979a; Henzi and Lucas, 
1980; Cheney, 1983; Pusey and Packer, 1986). Although most descriptions of such events focus on aggression directed toward the new individual from resident males in the group, the newcomer is sometimes the main initiator of aggressive interactions, threatening and attacking adults and juveniles of both sexes (van Noordwijk and van Schaik, 1985; Pereira, 1983; Smuts, 1985). Such immigration events are relatively common in the societies of savannah baboons.

During September 1989, a very aggressive adult male immigrated into a long-term study group during a period when blood samples were being obtained for endocrine analyses. This provided an unusual opportunity to examine predictions that stress-sensitive physiological variables would reflect the presence and intensity of aggressive social interactions associated with the immigration. In particular, we hypothesized that cortisol values would be higher and lymphocyte counts would be lower during the immigration period than at other times, that the class of individuals who experienced the most aggression during the immigration (females) would also experience the most pronounced differences in cortisol values and lymphocyte counts, and that individuals who were specific targets of attack by the immigrant would experience more pronounced effects than individuals who were not specific victims of attack.

\section{METHODS}

The subjects of this study were the members of three baboon groups that are a subset of the larger Amboseli basin baboon population in southern Kenya. All members of the study groups are identified visually by individual physical characteristics and have been part of longitudinal, observational research projects. The histories of almost all females, and of those males that were born into any of these study groups, are known since birth. These histories are based on daily records of demography, reproductive cycles, social interactions (including agonistic, grooming, and sexual behavior), and monthly evaluations of physical maturation (see, e.g., Altmann, Hausfater, and Altmann, 1988; Altmann and Muruthi, 1988).

The male, Hobbes, whose immigration provided the focus of the present investigation, was first identified by researchers when he was a subadult in one of the adjacent nonstudy groups. He was sighted a number of times during the months prior to his immigration. Upon his entry into Hook's Group (the study group in question), he was categorized as a young, 8-year-old adult, based on body size, dental emergence, canine length and condition, and the previous observations of him during subadulthood. As an immigrant male, Hobbes immediately became a subject of an ongoing behavioral study of adult males. These behavioral observations provided information on activity profiles and on agonistic and affiliative interactions. One hundred seventy-nine 30 -min focal samples 
(Altmann, 1974) were obtained on other adult males during the 18 months preceding Hobbes' immigration, and 14 samples were obtained on Hobbes during the 2 weeks subsequent to his immigration.

During 1989 and 1990, the hands-off observational project was supplemented by morphometric measurements, parasite evaluations, and collection of blood samples during a short period of anesthetization. Subjects were anesthetized with Telazol (tiletamine hydrochloride and zolazepam) injected from a propelled syringe fired from a blowgun at $10 \mathrm{~m}$. Animals were darted only when they were out of the sight of other individuals and when their backs were turned, so as to preclude anticipatory stress or loss of habituation. All subjects were darted between 7:30 AM and 10:30 AM to control for circadian fluctuations in hormone concentrations. Each subject is represented in the analysis by a single value for cortisol and a single lymphocyte count; no subject had been darted previously (although we note that repeated darting has no effect on cortisol or lymphocyte counts, R. M. Sapolsky, unpublished data).

A first blood sample was obtained at the earliest time that we could safely bleed subjects; this was always within $15 \mathrm{~min}$ of the darting (see Sapolsky, 1982; Sapolsky and Altmann, 1991 for details), and basal cortisol values thus obtained did not vary with length of time from the darting to first blood drawing. All blood samples were handled the same way throughout the sampling period. Samples were centrifuged on site and plasma was frozen in dry ice until its return to the United States. Cortisol concentrations were determined by radioimmunoassay as described in Krey et al. (1975), using antibody F21-53 (Endocrine Sciences, Tarzana, CA). Radioimmunoassay of testosterone was conducted as described in Gay and Kerlan (1978), using antiserum S250 generated in sheep against a testosterone-11-bovine serum albumin conjugatc. Testostcronc is the major androgen in baboons; small amounts of androstenedione and dehydroepiandrosterone (Snipes, Forest, and Migeon, 1969) also occur, but cross-reactivity of the antiserum with either of these androgens is less than $1 \%$. Coefficients of variation across and within assays were 0.08 and 0.04 , respectively $(N=3)$.

Immunological measures were based on lymphocyte, leukocyte, and red cell counts made from thin smears. Blood smears were made on site, dried, stained with Wright's stain (Sigma Chemical, St. Louis, MO), and stored frozen until their return to the United States. Differential counting of leukocytes (lymphocytes, neutrophils, basophils, and eosinophils) was carried out in 50 fields-of-vision/slide by a trained hematology technician making blind assessments. Data regarding a particular type of leukocyte are presented as number $/ 10,000$ red blood cells, rather than as the more traditional absolute number, because smears generated under field conditions were of uneven thickness. Numbers of red blood cells were determined by counting in 10 randomly chosen fields of vision. 
Very old animals (those over 6000 days of age) were deleted from the physiological analyses because basal cortisol concentrations are elevated in the aged of this population (Sapolsky and Altmann, 1991).

\section{RESULTS}

During the 2 weeks following Hobbes' immigration, the average rate at which he was involved in agonistic interactions (as per definitions in Hausfater, 1975) was 0.32 per minute, a significantly higher rate than the average of 0.072 per minute for all other males in Hook's Group during the period preceding Hobbes' immigration ( $t$ test, $p<0.004$ ). The maximum rate of agonistic interaction for any $30-\mathrm{min}$ sample on an adult male prior to Hobbes' immigration was 0.267 per minute. Females were disproportionately the victims in these interactions with Hobbes $(G=6.298$, $p<0.025$ ).

The physiological profiles of members of Hook's Group reflected the presumed stressfulness of the high rate of agonistic interactions. Basal concentrations of cortisol, the predominant glucocorticoid of primates, were higher in Hook's Group following Hobbes' immigration than in other groups or in Hook's Group at other times (Fig. 1a; $t$ test, $p<0.0008$ for comparison with the population as a whole). Moreover, the basal hypercortisolism was most pronounced among females, the class of individuals that were most subject to the stressfulness of Hobbes' immigration (Fig. $1 \mathrm{~b}$; males, $t$ test, $p<0.10$; females, $t$ test, $p<0.001$ ). Victims of Hobbes' aggression revealed a nonsignificant trend toward hypercortisolism relative to nonvictims (Fig. 1c; $t$ test, $p=0.2171$ ). Hobbes' own value was in the upper quartile for the whole population.

Given the well-established inhibitory effects of cortisol upon numbers of circulating lymphocytes, it is not surprising that the basal hypercortisolism was accompanied by a quantitative index of immune suppression. Circulating lymphocyte counts were suppressed during the immigration period (Fig. $2 \mathrm{a} ; t$ test, $p<0.01$ ), a result that was primarily due to females rather than males (Fig. 2b; females, $t$ test, $p<0.001$; males, $t$ test, $p<$ 0.29). Victims of Hobbes' aggression had lower counts than nonvictims

Fig. 1. Basal cortisol concentrations (mean $\pm \mathrm{SE}$ ) for baboons without and with the presence of the aggressive immigrant male as a stressor (labeled "No Hobbes" and "Hobbes present," respectively). (a) Data pooled for animals in other groups and for members of Hook's Group prior to Hobbes' immigration (solid bar), data for members of Hook's Group during the period in which Hobbes immigrated (hatched), and the value for Hobbes himself (open). (b) Comparative data for males and females (conventions as in a). (c) Members of Hook's Group darted during the immigration period who wcre not victims of attacks by Hobbes (solid) and members who were victims of attacks by Hobbes (hatched). (See text for details.) 

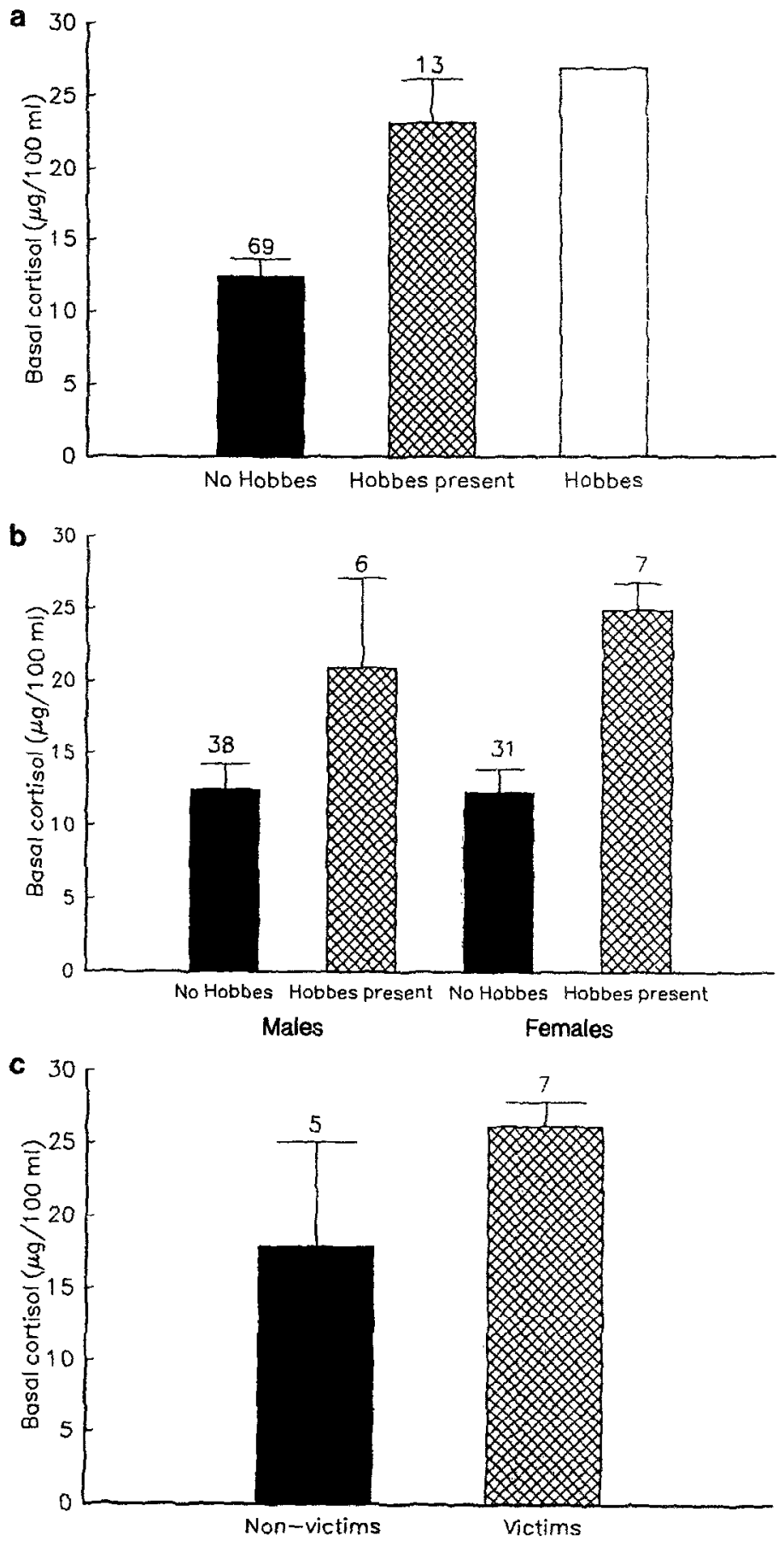

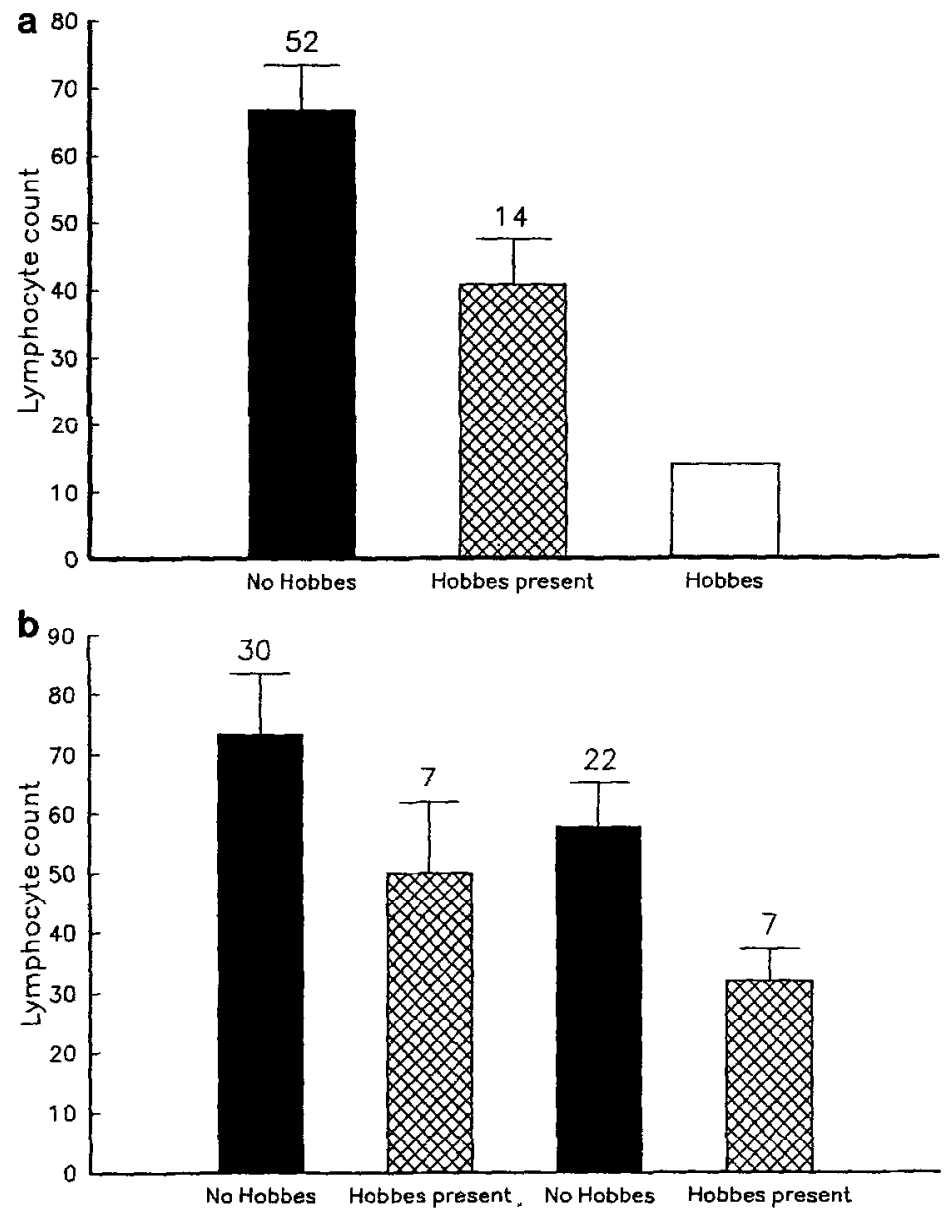

Males

Females

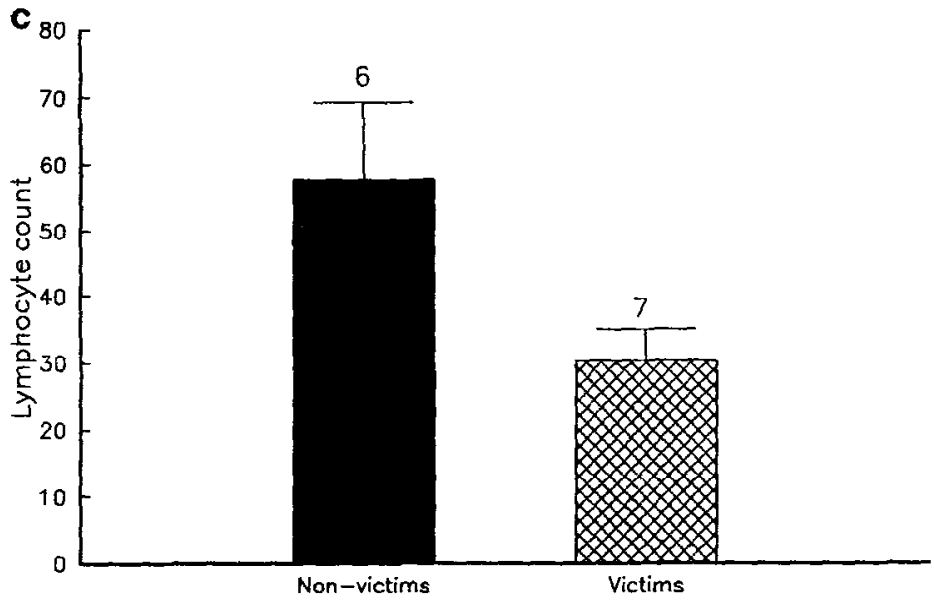

FIG. 2. Lymphocyte counts for members of Hook's Group without and with the stressor of the aggressive immigrant male. Conventions as described in the legend to Fig. 1. 


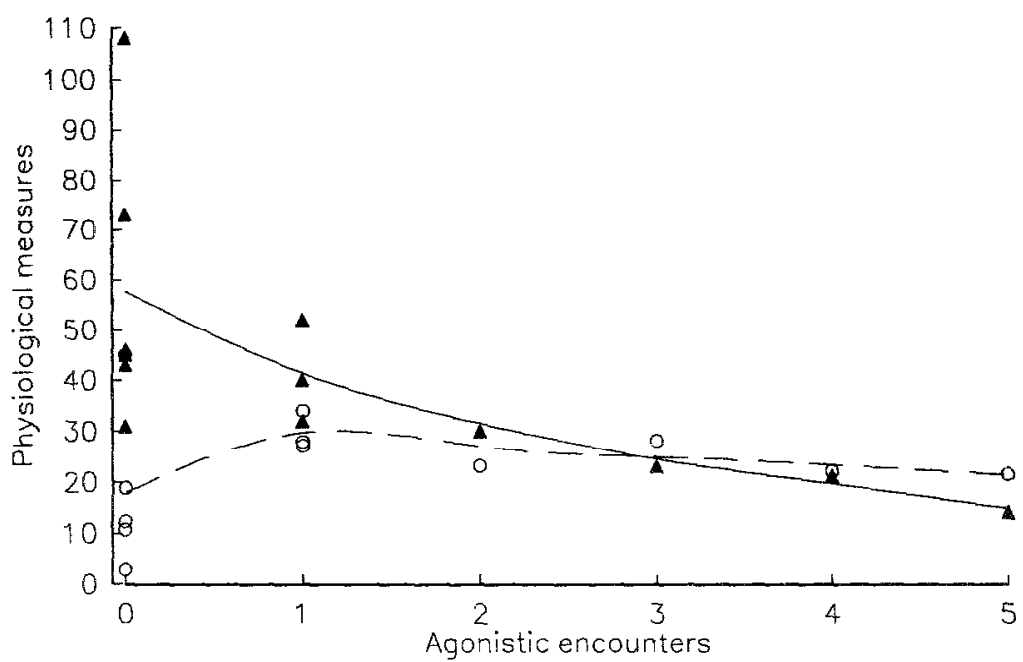

FiG. 3. Basal cortisol concentrations $(O)$ and lymphocyte counts $(\Delta)$ for members of Hook's Group as a function of number of agonistic encounters with Hobbes during the 2 weeks following his immigration.

(Fig. 2c; $t$ test, $p<0.04$ ), and the rate of agonistic encounters with Hobbes was inversely correlated with lymphocyte counts (Fig. $3 ; r=$ $-0.6367, p=0.0193, N=13$ ). Hobbes' own value was in the lowest quartile for the whole population.

In addition to the physiological findings, three of the females in Hook's Group experienced unexplained fetal losses during the weeks following Hobbes' entry. Nine days after Hobbes' entry, one of these females produced a preterm infant that died within 3 days of birth. The other two females experienced spontaneous abortion 22 and 39 days after the immigration, respectively. All three of these females were victims of attack by Hobbes at least two times during the observation period; one was attacked severely 2 days prior to the birth of her preterm infant, resulting in puncture wounds on the arms and a slit nostril. Cortisol concentrations and lymphocyte counts were not obtained for these three females.

Because testosterone concentrations, unlike those for cortisol, differ greatly between mature and immature animals, only adult males, (at least 8 years of age) could be used for analysis. Few adult males in Hook's Group were sampled during the immigration period, precluding comparisons of testosterone concentrations from that period with others. We note, however, that the mean and median testosterone concentrations were 0.83 and $0.60 \mathrm{ng} / \mathrm{ml}$, respectively, for the pooled sample of all aduit males $(N=26)$, and the highest concentration for all males was Hobbes' value, which at $2.70 \mathrm{ng} / \mathrm{ml}$ was almost $50 \%$ higher than the next highest value $(1.98 \mathrm{ng} / \mathrm{ml})$. 


\section{DISCUSSION}

The elevation of basal cortisol concentrations following the immigration of Hobbes is not surprising and is the strongest indicator of the stressfulness of the immigration period. Glucocorticoids such as cortisol are secreted in response to a broad range of physical and psychological stressors, and basal hypersecretion of these hormones is among the most stable endocrine markers of sustained stress.

Further, the magnitude of glucocorticoid secretion during a stressor can discriminate among the intensities of both physiological and psychological stressors (e.g., Dallman et al., 1987; Levine, Weiner, and Coe, 1989). Consistent with this sensitivity of responsiveness, cortisol hypersecretion in the present study was most pronounced among the females, the most persistent targets of Hobbes' stressful attacks.

A variety of stressors can potently suppress immune function, and in agreement with this, the immigration of Hobbes was associated with reduced lymphocyte counts. Whereas most studies of the effects of stress upon immunity examine functional indices of immune competence (e.g., mitogen stimulation tests, antibody generation, cytokine responsiveness), our field conditions limited us to this rather crude quantitative measure of numbers of cells. Nonetheless, the data strongly indicate the stressfulness of the male's immigration. Moreover, in agreement with the general sensitivity of such a measure to the magnitude of a stressor (Munck, Guyre, and Holbrook, 1984), the decline was more pronounced among females than males, was most pronounced among the victims of Hobbes' aggression, and was correlated with frequency of attack. The most proximal cause of the suppressed counts is not clear, but might involve the elevated cortisol concentrations. While glucocorticoids do not appear to mediate the suppressive effects of stress upon immune function, they do seem critical to the effects of stress upon numbers of circulating lymphocytes (Keller, Weiss, Schleifer, Miller, and Stein, 1983). In nonhuman primates and in humans, this is accomplished primarily by sequestering lymphocytes out of the circulation (Munck et al., 1984; Cupps and Fauci, 1982).

For females, the endocrine and immunological effects of an aggressive immigrant may be considerably augmented by the risk of spontaneous abortion or infant death as a result of severe attack (Pereira, 1983; Shopland, 1982). On the basis of the low natural rate of spontaneous abortion in this population (Altmann et al., 1988), and the previous association of spontaneous abortion with extreme aggression by an immigrant male (Pereira, 1983), we consider that some or all of the fetal losses that were associated with Hobbes' immigration were a result of Hobbes' aggressive attacks.

Abortions create increased reproductive opportunities when the abort- 
ing female resumes cycling (Hrdy and Hausfater, 1984). Whether the attacker benefits from such opportunities depends partially on whether the aggression inhibits the development of affiliative bonds between the immigrant male and resident females: such bonds have been demonstrated to be an important component of male mating success (Strum, 1982; Rasmussen, 1983; Smuts, 1985). In the present case, when the aborting females resumed cycling, Hobbes was the first recorded sexual consort for one of them, and the second for another. He was not seen consorting with the third.

Hobbes' aggression may have afforded further reproductive advantages through the attainment of high dominance status; he became the highest ranking male in the group within 1 week of entry. In Amboseli (Hausfater, 1975), as in many (Bulger and Hamilton, 1988; Samuels, Silk, and Rodman, 1984; Chapais, 1983; Packer, 1979b) though not all (Strum, 1982; Smuts, 1985; Taub, 1980) primate populations, agonistic dominance rank is positively correlated with mating success.

Despite potential reproductive advantages that may accrue, the stressors for a male who behaves very aggressively during immigration are probably both psychological (e.g., the uncertainty inherent in frequent fights) and physical (the demands of fighting and harassment). Insofar as the physiological data reflect the stressfulness of the period, Hobbes appeared to be at least as stressed as were the individuals who were victims of his aggression; his circulating basal cortisol concentrations were in the highest quartile of all individuals, while his lymphocyte counts were in the lowest quartile.

Hobbes had testosterone concentrations far in excess of other males. These high values are probably a consequence, rather than a cause, of his high rates of aggression. As evidence, among primates, both excrcise and aggressive interactions increase testosterone concentrations (Perachio, 1978; Elias, 1981; Sutton, Coleman, Casey, and Lazarus, 1973; Davies and Few, 1973; Dessypris, Kuoppasalmi, and Adlercreutz, 1976; Kuoppasalmi, Naveri, Rehunen, Harkonen, and Adlercreutz, 1976), while exogenous manipulations of testosterone concentrations within the physiological range typically do not cause parallel changes in rates of aggression (Dixson, 1979; Rose, 1985).

Elevated levels of aggression are common during male immigration in cercopithecine primate groups (Pusey and Packer, 1986), but immigration is not always accompanied by the extreme levels of aggression described here, and immigrant males are sometimes relatively nonaggressive (Colvin, 1983; Cheney, 1983; Strum, 1982; Smuts, 1985). In spite of the apparent benefits a male experiences as a result of being extremely aggressive upon entering a group, he clearly also experiences some serious short-term costs. These short-term costs may translate into long-term ones if cortisol hypersecretion becomes chronic, if depressed immune function 
results in illness or infection, if serious injury occurs, or if the immigrant fails to form affiliative bonds with group members. This suggests that while extremely aggressive behavior during immigration may obtain a reproductive advantage for the immigrant male, the behavior entails physiological, energetic, and behavioral risks, for the immigrant and for the residents of the group into which he enters. The fact that not all immigration events are accompanied by elevated levels of aggression suggests that there is a large range of behavior an immigrant can express; the relative advantages and costs of various types of immigrant behavior remain to be determined.

\section{ACKNOWLEDGMENTS}

We are grateful for sponsorship, assistance, or permits in Kenya to the Office of the President, Republic of Kenya, to the Kenya Wildlife Services, its Amboseli staff and Wardens, and its Director, R. Leakey, and to the Institute of Primate Research, its staff, and its former and present Directors, J. Else and M. Isahakia. The field work further depended directly on a number of people in Kenya, especially S. Altmann, D. Chai, R. Eley, R. Kones, P. Muruthi, R. S. Mututua, G. Reid, S. Sayiallel, K. Snyder, L. Share, J. Somen, and M. Suleman. Lymphocyte counts were done by T. Ha. Graphics assistance was generously provided by $\mathrm{L}$. Gale. Financial support for the field work was provided by the Leakey Foundation and Sigma Xi (S.C.A.), Harry Frank Guggenheim Foundation (R.M.S.), and the Chicago Zoological Society (J.A.). This manuscript was prepared while J.A. was a Fellow at the Center for Advanced Study in the Behavioral Sciences where financial support for her fellowship was provided by the John D. and Catherine T. MacArthur Foundation.

\section{REFERENCES}

Altmann, J. (1974). Observational study of behavior: Sampling methods. Behaviour 69, $227-267$.

Altmann, J., Hausfater, G., and Altmann, S. A. (1988). Determinants of reproductive success in savannah baboons. In T. H. Clutton-Brock (Ed.), Reproductive Success, pp. 403-418. Univ. Chicago Press, Chicago.

Altmann, J., and Muruthi, P. (1988). Differences in daily life between semi-provisioned and wild-feeding baboons. Am. J. Primatol. 15, 213-221.

Bulger, J., and Hamilton, W. J., III (1988). Inbreeding and reproductive success in a natural chacma baboon, Papio cynocephalus ursinus, population. Anim. Behav. 36, 574-578.

Chapais, B. (1983). Male dominance and reproductive activity in thesus monkeys. In R. A. Hinde (Ed.), Primate Social Relationships: An Integrated Approach, pp. 267-271. Blackwell, Oxford.

Cheney, D. L. (1983). Proximate and ultimate factors related to the distribution of male migration. In R. A. Hinde (Ed.), Primate Social Relationships: An Integrated Approach, pp. 241-249. Blackwell, Oxford.

Colvin, J. (1983). Influences of the social situation on male emigration. In R. A. Hinde (Ed.), Primate Social Relationships: An Integrated Approach, pp. 160-171. Blackwell, Oxford.

Cupps, T., and Fauci, A. (1982). Corticosteroid-mediated immunoregulation in man. Immunol. Rev. 65, 133-151.

Dallman, M., Akana, S., Cascio, C.. Darlington, D., Jacobson, L., and Levin, N. (1987). 
Regulation of ACTH secretion: Variations on a theme of B. Recent Prog. Horm. Res. 43, 113-168.

Davies, C., and Few, J. (1973). Effects of exercise on adrenocortical function. J. Appl. Physiol. 35, 887-893.

Dessypris, A., Kuoppasalmi, K., and Adlercreutz, H. (1976). Plasma cortisol, testosterone, androstenedione and luteinizing hormone in a non-competitive marathon run. $I$. Steroid. Biochem. 7, 33-42.

Dittus, W. (1977). The social regulation of population density and age-sex distribution in the toque monkey. Behaviour 63, 281-322.

Dixson, A. (1979). Androgens and aggressive behavior in primates: A review. Aggressive Behav. 6, 37-52.

Elias, M. (1981). Cortisol, testosterone and testosterone-binding globulin responses to competitive fighting in human males. Aggressive Behav. 7, 215-222.

Gay, B., and Kerlan, J. (1978). Serum LH and FSH following passive immunization against circulating testosterone in the intact male rat and orchidectomized rats bearing subcutaneous silastic implants of testosterone. Arch. Androl. 1, 257-266.

Hausfater, G. (1975). Dominance and reproduction in baboons (Papio cynocephalus). Contributions to Primatology, Vol. 7. Karger, Basel.

Henzi, S. P., and Lucas, J. W. (1980). Observations on the inter-troop movements of adult vervet monkeys (Cercopithecus aethiops). Folia Primatol. 33, 220-235.

Hrdy, S. B., and Hausfater, G. (1984). Comparative and evolutionary perspectives on infanticide: An introduction and overview. In G. Hausfater and S. B. Hrdy (Eds.), Infanticide: Comparative and Evolutionary Perspectives, pp. xii-xxxv. Aldine, Hawthome, NY.

Keller, S. E., Weiss, J. M., Schleifer, S. J., Miller, N, E., and Stein, M. (1983). Siressinduced suppression of immunity in adrenalectomized rats. Science 221, 1301-1304.

Krey, L., Lu, K., Butler, W., Hotchkiss, J., Piva, F., and Knobil, E. (1975). Surgical disconnections of the medial basal hypothalmus and pituitary function in the rhesus monkey. II. GH and cortisol secretion. Endocrinology 96, 1088-1096.

Kuoppasalmi, K., Naveri, H., Rehunen, S., Harkonen, M., and Adlercreutz, H. (1976). Effect of strenuous anaerobic running exercise on plasma growth hormone, cortisol, LH testosterone, androstenedione, estrone, and estradiol. J. Steroid Biochem. 7, 823836.

Levine, S., Wiener, S., and Coe, C. (1989). The psychoneuroendocrinology of stress-A psychobiological perspective. In F. Brush Levine (Ed.), Psychoendocrinology, pp. 121145. Academic Press, New York.

Munck, A., Guyre, P., and Holbrook, N. (1984). Physiological functions of glucocorticoids during stress and their relation to pharmacological actions. Endocr. Rev. 5, 25-41.

Packer, C. (1979a). Inter-troop transfer and inbreeding avoidance in Papio anubis. Anim. Behav. 27, 1-36.

Packer, C. (1979b). Male dominance and reproductive activity in Papio anubis. Anim. Rehav. 27, 37-45.

Perachio, A. (1978). Hypothalamic regulation of behavioural and hormonal aspects of aggression and sexual performance. In $\mathrm{D}$. Chivers and $\mathbf{J}$. Herbert (Eds.), Recent Advances in Primatology, Vol. 1., pp. 549-565. Academic Press, London.

Pereira, M. E. (1983). Abortion following the immigration of an adult male baboon (Papio cynocephalus). Am. J. Primatol. 4, 93-98.

Pusey, A. E., and Packer, C. (1986). Dispersal and philopatry. In B. B. Smuts, D. L.Cheney, R. M. Seyfarth, R. W. Wrangham, and T. T. Struhsaker, (Eds.), Primate Societies, pp. 250-266. Univ. Chicago Press, Chicago.

Rasmussen, K. R. (1983). Influence of affiliative preferences upon the behaviour of male 
and female baboons during sexual consortships. In R. A. Hinde (Ed.), Primate Social Relationships: An Integrated Approach, pp. 116-127. Blackwell, London.

Rose, R. (1985). Psychoendocrinology. In J. Wilson and D. Foster (Eds.), Williams Textbook of Endocrinology, pp. 653-681. Saunders, Philadelphia.

Samuels, A., and Altmann, J. (1991). Baboons of the Amboseli Basin: Demographic statics and dynamics. Int. J. Primatol.12, 1-19.

Samuels, A., Silk, J. and Rodman, P. (1984). Changes in the dominance rank and reproductive behavior of male bonnet macaques (Macaca radiata). Anim. Behav. 32, 9941003.

Sapolsky, R. M. (1982). The endocrine stress-response and social status in the wild baboon. Horm. Behav. 15, 279-292.

Sapolsky, R. M., and Altmann, J. (1991). Incidences of hypercortisolism and dexamethasone resistance increase with age among wild baboons. Biol. Psychiatry, 30, 1008- 1016.

Shopland, J. M. (1982). An intergroup encounter with fatal consequences in yellow baboons (Papio cynocephalus). Am. J. Primatol. 3, 263-266.

Smuts, B. B. (1985). Sex and Friendship in Baboons. Aldine, Hawthorne, NY.

Snipes, C., Forest, M.. and Migeon, C. (1969). Plasma androgen concentrations in several species of Old and New World monkeys. Endocrinology 85, 941-945.

Strum, S. C. (1982). Agonistic dominance in male baboons: An alternative view. Int. J. Primatol. 5, 93-109.

Sutton, J., Coleman, M., Casey, J., and Lazarus, L. (1973). Androgen responses during physical exercise. Br. Med. J. 163, 520-528.

Taub, D. (1980). Female choice and mating strategies among wild Barbary macaques (Macaca sylanus L.). In D. G. Lindberg (Ed.), The Macaques: Studies in Ecology, Behavior, and Evolution, pp. 287-344. Van Nostrand-Reinhold, New York.

van Noordwijk, M. A., and van Schaik, C. P. (1985). Male migration and rank acquisition in wild long-tailed macaques, Macaca fascicularis. Anim. Behav. 33, 849-861. 